\title{
Disruptive Behavior Disorder
}

National Cancer Institute

\section{Source}

National Cancer Institute. Disruptive Behavior Disorder. NCI Thesaurus. Code C99753.

A classification of disorders in the Diagnostic and Statistical Manual of Mental Disorders (DSM) that are usually diagnosed in infancy, childhood or adolescence and are characterized by an individual's inability to behave in a cooperative manner. 